\title{
Realizing the vision of patient-relevant clinical research
}

\author{
Kirsten Patrick MBBCh DA
}

See also page E375 and www.cmaj.ca/lookup/doi/10.1503/cmaj.150858 and page 1065 and www.cmaj.ca/lookup/doi/10.1503/cmaj.160692

I ncentive payments to primary care physicians for providing care to patients with multiple chronic conditions in British Columbia did not have a significant impact on patients' primary care contacts, continuity of care or costs related to their management, according to a new study by Lavergne and colleagues. ${ }^{1}$ In a linked commentary, Kiran suggests that the problem likely lies with the implementation of policy that was poorly planned and inadequately evidence based. ${ }^{2}$ In both articles, there is a striking absence of any reference to patients, beyond defining the patient population and acknowledging that patients with multimorbidity are seen by physicians as being more difficult to care for than "easier, healthier patients." The authors studied patients in primary care, but the intervention was all about physicians, the government and money, and the outcomes were almost certainly not patient-relevant.

To be fair, BC implemented incentive payments well before "patient-relevant outcomes" became the term de jour, following the creation of the Patient-Centered Outcomes Research Institute (PCORI) by the 2010 Patient Protection and Affordable Care Act in the United States. If the 90s and the 00s were all about the rise of civil society shaping health, then this decade has surely been about acknowledging the voice of the patient. Involvement of patients in the design of both health services and research is becoming more commonplace. However, we still have some way to go before meaningful patient involvement in research becomes routine, as it should.

Thankfully, we have moved on from the why of patient involvement toward the how and the who. Public involvement in research is now mandated by many funding agencies. Involving patients and other lay stakeholders in research planning gives patients knowledge and influence, and it gives researchers greater insight into their area of study. ${ }^{3}$ However, involving patients adds complexity and expense to projects, and researchers and the public may be frustrated by insufficient training.

Canada's Strategy for Patient-Oriented Research (SPOR), published in 2011, laid out the vision and plan of the Canadian Institutes of Health Research (CIHR) to enhance patient care through the levers of research."4 The strategy rightly identified training and capacity-building as essential to fulfilling the vision. However, the financial commitments required to build capacity represent a barrier to fulfillment of the vision. ${ }^{5}$

What's required is a major shift in the way studies are planned and conducted, and in which medical students and new researchers are taught and mentored. What's more, patients involved in research planning also need education in the mechanics and norms of clinical research. PCORI has committed to projects that enhance the engagement of patients and other stakeholders in research design by offering awards for projects that are "not themselves research studies but rather are designed to encourage better integration of patients and other stakeholders into the research process." "The European Patients' Academy on Therapeutic Innovation recently graduated a first wave of students from its expert course for patients and patient representatives on the medicines research and development process.

There's no clear gold standard yet for how to undertake patient-relevant research. Best practice is still being developed. Indeed, there is unlikely to be a universally applicable formula. For each step in the research process, investigators need to consider how best to involve patients in planning and decisions. ${ }^{7}$ For patient-relevant research to be meaningful, patient and public engagement in research cannot comprise a token lay person on a research ethics review board. Patients and their caregivers must be involved in decision-making at all steps in the research process, from design to choice of primary and secondary outcomes, through dissemination and implementation. ${ }^{8}$

The external committee advising the CIHR on SPOR called for training and career development to be "a shared responsibility between all relevant stakeholders." ${ }^{\circ}$ As a journal that publishes clinical research, $C M A J$ is a stakeholder in this process. Part of CMAJ's mission is to promote the health and well-being of the Canadian public; we therefore support enhanced patient engagement in research that is about patients. As we appraise research that is submitted to the journal, we will consider carefully methods used to involve public and patient representatives in design and implementation.

\section{References}

1. Lavergne MR, Law MR, Peterson S. A population-based analysis of incentive payments to primary care physicians for the care of patients with complex disease. CMAJ 2016;188:E375-83.

2. Kiran T. Toward evidence-based policy. CMAJ 2016;188:1065-6.

3. Brett J, Staniszewska S, Mockford C, et al. A systematic review of the impact of patient and public involvement on service users, researchers and communities. Patient 2014;7:387-95.

4. Canada's Strategy for Patient-Oriented Research: improving health outcomes through evidence-informed care. Ottawa: Canadian Institutes of Health Research; 2011. Available: www.cihr-irsc.gc.ca/e/44000.html (accessed 2016 Sept. 12).

5. External Advisory Committee Report: training and career development in patientoriented research. Ottawa: Canadian Institutes of Health Research; updated 2013. Available: www.cihr-irsc.gc.ca/e/47693.html (accessed 2016 Sept. 12).

6. Pipeline to proposal awards. Washington: Patient-Centered Outcomes Research Institute; updated 2016. Available: www.pcori.org/funding-opportunities/programmaticfunding (accessed 2016 Sept. 12).

7. Oliver S, Liabo K, Stewart R, et al. Public involvement in research: making sense of the diversity. J Health Serv Res Policy 2015;20:45-51.

8. Patient engagement. Ottawa: Canadian Institutes of Health Research; updated 2014 Available: www.cihr-irsc.gc.ca/e/45851.html (accessed 2016 Sept. 12)

Competing interests: See www.cmaj.ca/site/misc/cmaj_staff.xhtml

Affiliation: Deputy Editor, $C M A J$

Correspondence to: $C M A J$ editor, pubs@cmaj.ca

CMAJ 2016. DOI:10.1503/cmaj.161084 